\section{SOI: $1.1 /$ TAS DOI: $10.15863 / \mathrm{TAS}$ \\ International Scientific Journal Theoretical \& Applied Science}

p-ISSN: 2308-4944 (print) e-ISSN: 2409-0085 (online)

Year: 2017 Issue: 03 Volume: 47

\section{Denis Chemezov}

Master of Engineering and Technology, Corresponding Member of International Academy of Theoretical and Applied Sciences, Lecturer of Vladimir Industrial College, Russian Federation chemezov-da@yandex.ru

SECTION 25. Technologies of materials for the light and textile industry.

\title{
THE TECHNOLOGICAL PROCESS OF THE MANUFACTURING A FILM SCALE OF THE INSTRUMENT PANEL OF VEHICLE ON THE AUTOMATED LINE SAKURAI
}

Abstract: The article is presented the sequence of the manufacturing film scales of the instrument panel of vehicle in conditions of the automated production.

Key words: a printing, a stencil, a doctor blade, a film scale.

Language: Russian

Citation: Chemezov D (2017) THE TECHNOLOGICAL PROCESS OF THE MANUFACTURING A FILM SCALE OF THE INSTRUMENT PANEL OF VEHICLE ON THE AUTOMATED LINE SAKURAI. ISJ Theoretical \& Applied Science, 03 (47): 46-50.

Soi: http://s-o-i.org/1.1/TAS-03-47-10 Doi: crossef https://dx.doi.org/10.15863/TAS.2017.03.47.10

\section{ТЕХНОЛОГИЧЕСКИЙ ПРОЦЕСС ИЗГОТОВЛЕНИЯ ПЛЕНОЧНОЙ ШКАЛЫ ПАНЕЛИ ПРИБОРОВ АВТОМОБИЛЯ НА АВТОМАТИЧЕСКОЙ ЛИНИИ SAКURAI}

Аннотация: В статье представлена последовательность изготовления пленочных шкал панели приборов автомобиля в условиях автоматизированного производства.

Ключевые слова: печать, трафарет, ракель, пленочная шкала.

\section{Введение}

Серийное изготовление элементов (шкалы) панели приборов автомобилей [1] разделяется на вспомогательное производство (изготовление трафаретов [2]) и основное производство (печать [3]).

Процесс изготовления трафарета, из моноволоконной полиэфирной ткани, для печати шкалы панели приборов автомобиля представлен в работе [4]. Печать шкал панелей приборов автомобилей выполняется по изготовленным трафаретам на специальном технологическом оборудовании.

Для выполнения трафаретной печати пленочных шкал и светофильтров на ОАО «Завод «Автоприбор» (г. Владимир, Россия) [5] введена в эксплуатацию автоматическая линия на базе автомата MF-80 фирмы «SAKURAI» (Япония) [6] и сушильных устройств фирмы «Natgraph» (Великобритания).

Плоскопечатный автомат модели MF-80 с вакуумным столом предназначен для печати листовых материалов толщиной от 0.1 до 3 мм. Автомат для печати имеет следующие технические характеристики: максимальный формат листа $-800 \times 600$ мм, минимальный формат листа $-350 \times 270$ мм, максимальный формат печати $-800 \times 585$ мм, внешний размер печатной формы - $1100 \times 1000$ мм, высота стопы самонаклада [7] - 620 мм, поле захвата клапанов - 6-8 мм, возможность регулировки клапанов по X-Y - 15 мм, скорость работы - 3600 лист/час, энергопотребление -7.75 кВт.

Сушильные устройства предназначены для отверждения красок, применяемых при отделке печатной продукции.

Трафаретной печати на автомате модели MF-80 подвергается термопластичный материал поликарбонат. Поликарбонаты относятся к аморфным пластикам. Поликарбонатная пленка обладает высокой химической стойкостью, термостойкостью, прочностью к разрыву и абразивному воздействию, гибкостью.

Соблюдение технологического процесса на всех этапах и полный контроль параметров оборудования обеспечивается при выполнении последовательности действий представленных ниже. 


\begin{tabular}{|c|c|c|c|c|c|c|}
\hline Impact Factor: & $\begin{array}{l}\text { ISRA (India) } \\
\text { ISI (Dubai, UAE } \\
\text { GIF (Australia) } \\
\text { JIF }\end{array}$ & $\begin{array}{l}=1.344 \\
=0.829 \\
=0.564 \\
=1.500\end{array}$ & $\begin{array}{l}\text { SIS (USA) } \\
\text { PИHЦ (Russia) } \\
\text { ESJI (KZ) } \\
\text { SJIF (Morocco) }\end{array}$ & $\begin{array}{l}=0.912 \\
=0.234 \\
=1.042 \\
=\mathbf{2 . 0 3 1}\end{array}$ & $\begin{array}{l}\text { ICV (Poland) } \\
\text { PIF (India) } \\
\text { IBI (India) }\end{array}$ & $\begin{array}{l}=6.630 \\
=1.940 \\
=4.260\end{array}$ \\
\hline
\end{tabular}

Технологический процесс изготовления шкалы

Технологический процесс изготовления пленочной шкалы панели приборов автомобиля на станочной автоматической линии SAKURAI представлен в табл. 1.

Таблица 1

Последовательность технологического процесса изготовления пленочной шкалы панели приборов автомобиля на автоматической линии SAKURAI.

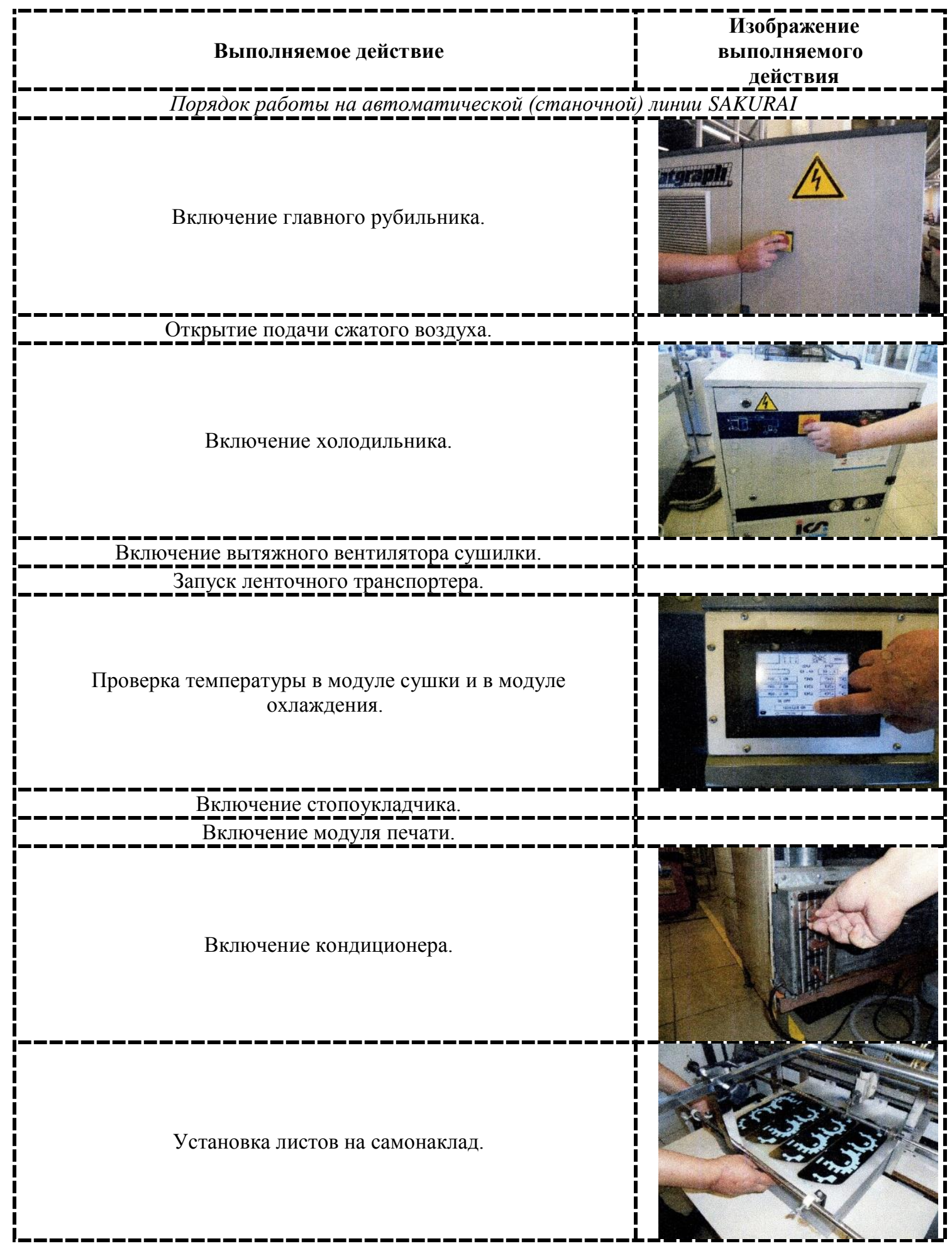




\begin{tabular}{|c|c|c|c|c|c|c|}
\hline Impact Factor: & $\begin{array}{l}\text { ISRA (India) } \\
\text { ISI (Dubai, UAE } \\
\text { GIF (Australia) } \\
\text { JIF }\end{array}$ & $\begin{array}{l}=1.344 \\
=0.829 \\
=0.564 \\
=1.500\end{array}$ & $\begin{array}{l}\text { SIS (USA) } \\
\text { PИНЦ (Russia) } \\
\text { ESJI (KZ) } \\
\text { SJIF (Morocco) }\end{array}$ & $\begin{array}{l}=0.912 \\
=0.234 \\
=1.042 \\
=\mathbf{2 . 0 3 1}\end{array}$ & $\begin{array}{l}\text { ICV (Poland) } \\
\text { PIF (India) } \\
\text { IBI (India) }\end{array}$ & $\begin{array}{l}=6.630 \\
=1.940 \\
=4.260\end{array}$ \\
\hline
\end{tabular}

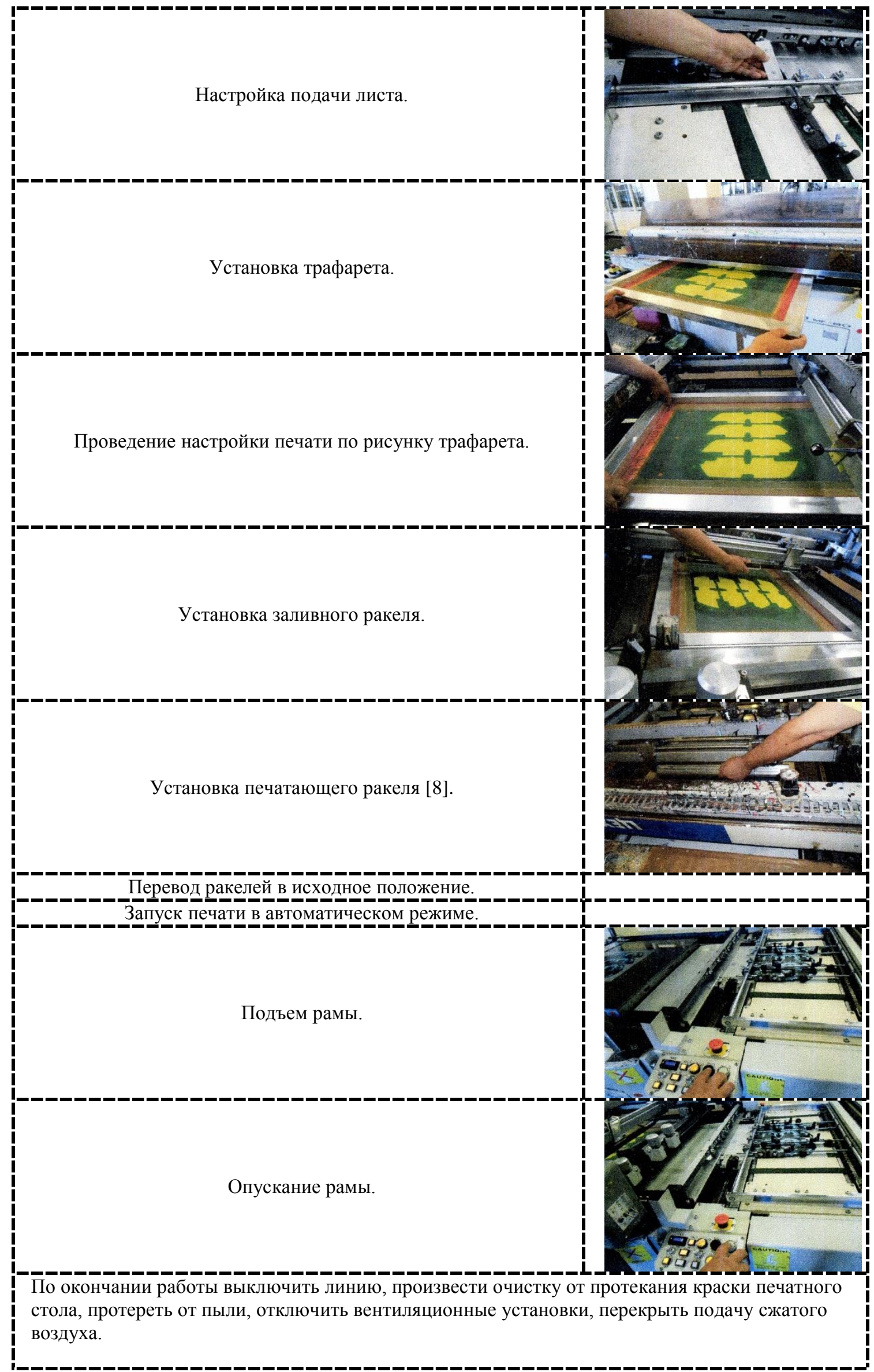

ISPC Technological breakthrough in science, Philadelphia, USA 


\begin{tabular}{|c|c|c|c|c|c|c|}
\hline Impact Factor: & $\begin{array}{l}\text { ISRA (India) } \\
\text { ISI (Dubai, UAE } \\
\text { GIF (Australia) } \\
\text { JIF }\end{array}$ & $\begin{array}{l}=1.344 \\
=0.829 \\
=0.564 \\
=1.500\end{array}$ & $\begin{array}{l}\text { SIS (USA) } \\
\text { PИНЦ (Russia) } \\
\text { ESJI (KZ) } \\
\text { SJIF (Morocco) }\end{array}$ & $\begin{array}{l}=0.912 \\
=0.234 \\
=1.042 \\
=\mathbf{2 . 0 3 1}\end{array}$ & $\begin{array}{l}\text { ICV (Poland) } \\
\text { PIF (India) } \\
\text { IBI (India) }\end{array}$ & $\begin{array}{l}=6.630 \\
=1.940 \\
=4.260\end{array}$ \\
\hline
\end{tabular}

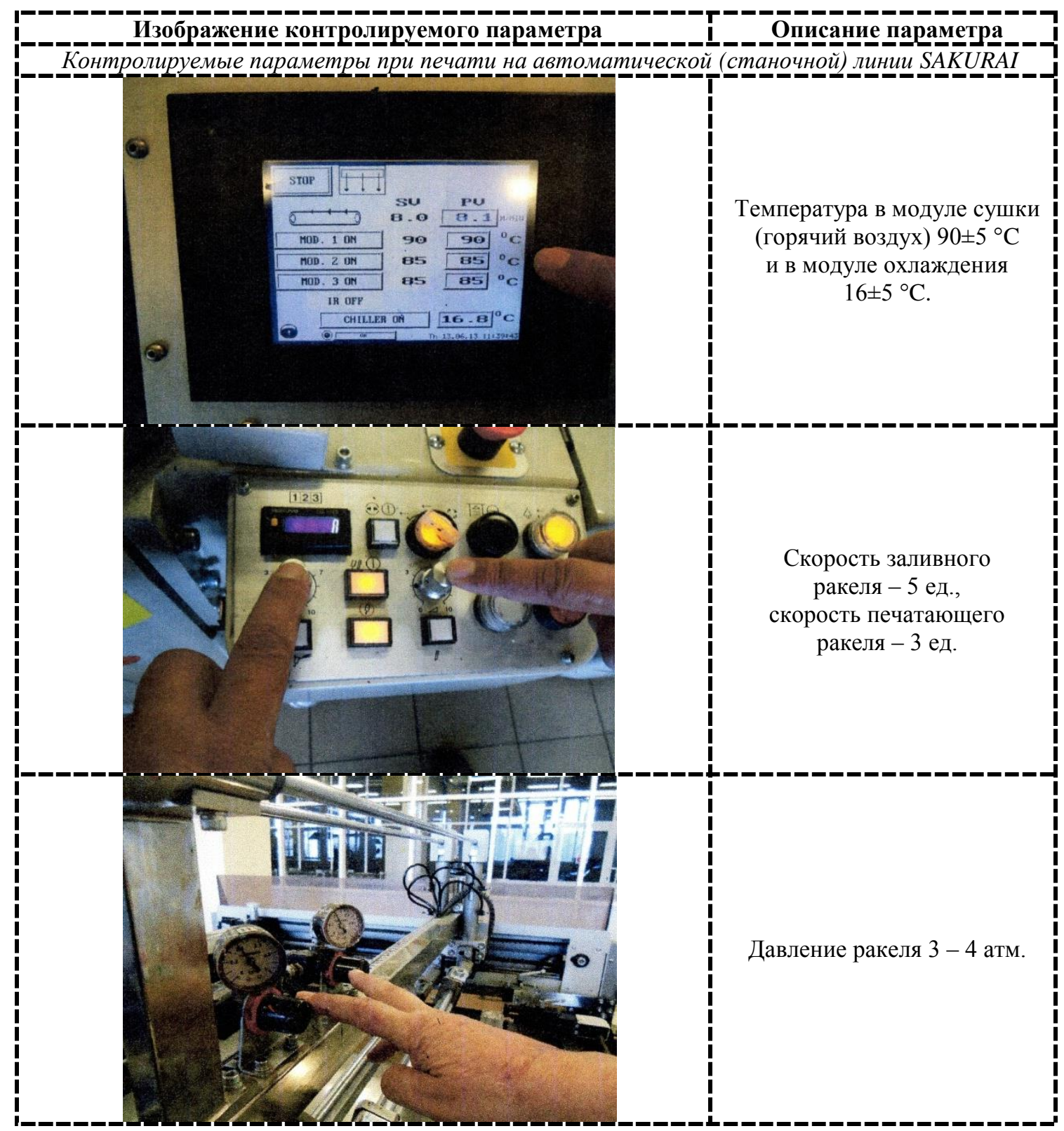

Заключение

Повышение технологичности, снижение издержек производства и повышение производительности - неотъемлемая часть политики ОАО «Завод «Автоприбор» при реализации инвестиционной программы с 2008 года. Высокое качество изготовления шкал на поликарбонатной пленке обеспечивается высокоточным автоматическим оборудованием. Тем самым сокращается количество основного производственного персонала и соответственно снижается производственный брак продукции, вызванный человеческим фактором.

\section{References:}

1. (2017) Instrument panel. Available: https://ru.wikipedia.org/wiki/Приборная_пане ль (Accessed: 13.03.2017).
2. (2017)

Stencil.

Available: https://en.wikipedia.org/wiki/Stencil (Accessed: 13.03.2017). 


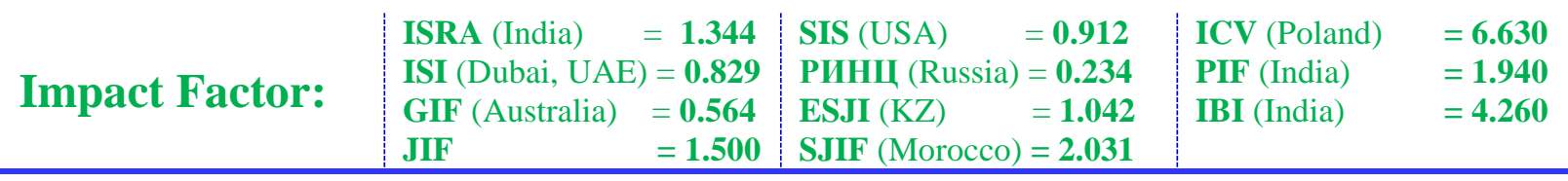

3. (2017) Screen printing. Available: https://en.wikipedia.org/wiki/Screen_printing (Accessed: 13.03.2017).

4. Chemezov D, Kiseleva E (2016) A stencil manufacture in the conditions of JSC Zavod «Avtopribor». ISJ Theoretical \& Applied Science, 12 (44): 79-83. Soi: http://s-oi.org/1.1/TAS-12-44-16

Doi: http://dx.doi.org/10.15863/TAS.2016.12.44.16

5. (2017) Avtopribor. Available: http://avtopribor.ru (Accessed: 13.03.2017).
6. (2017) Sakurai Graphic Systems Corporation. Available: http://www.sakuraigs.co.jp/en/products/ (Accessed: 13.03.2017).

7. (2017) Feeder. Available: http://patlah.ru/etm/etm-

01/teh\%20reklama/poligraf/pechat_ofset/pechat ofset-06.htm (Accessed: 13.03.2017).

8. (2017) Doctor blade in screen printing. Available:

http://www.screenprint.su/support/learning6.ht ml (Accessed: 13.03.2017). 